are now being made into the relations between solar radiation and ozone should throw a great deal of light on the effect of sunspots on weather.

The problem is complicated by terrestrial effects, such as the lag in changes of world temperature caused by the masses of polar ice and by the movements of powerful ocean currents, or the disturbing effects of great volcanic eruptions. All these factors will need to be taken into account before long-range forecasts can attain a really effective precision, but $\mathrm{Mr}$. Inigo Jones gives a number of examples to support his view that in Australia at least the major control of weather is exerted by the sun.

\section{Canned Fruit and Vegetables}

THE processes that made the preservation of fruit 1 and vegetables possible were discovered in France more than a century ago, but although numerous canning factories have been in operation in several European countries, America, and parts of the British Empire, it is only during the last ten years that any have been built in England. However, 53 such factories were in operation in this country by 1931 .

The quantity of canned fruit imported into England has shown an enormous increase in recent years. In view of this greater demand, the home industry has every prospect of success, provided the grower will produce the right type of fruit and vegetable. To meet this need, the Ministry of Agriculture has published an illustrated bulletin (No. 45) entitled "Fruit and Vegetable Production for Commercial Canning" (London : H.M. Stationery Office, 1s. 3d.).

Plums are by far the most important tree fruit for canning purposes, the use of cherries being somewhat restricted owing to the tendency of the juice to act on the metal container and the difficulty of finding a suitable variety. As regards the commonly grown soft fruits, the majority may be successfully canned if firm, clean fruit is selected. Up to the present, peas are the only vegetable that has been canned in any quantity, but the possibilities of extending the industry to include other vegetables are indicated.

Production for the cannery is an entirely different proposition from production for the fresh market, and it is essential that the grower should recognise this from the start. On the whole, it would seem most suited to large-scale producers with mechanical methods of cultivation, as regular, standardised consignments are required and costs must be kept as low as possible. From the long experience obtained in other countries, the desirability of contract growing is indicated. Various methods of this system are discussed, but it is evident that special arrangements will need to be worked out to meet the particular requirements of the different crops. Some such methods should, however, do much to promote the development of the industry and give confidence to the growers.

\section{Standardised Preparations of Vitamins $A$ and $D$}

$\mathrm{W}$ E are glad to note that British manufacturers have taken full advantage of the recent striking advances in our knowledge of the fat-soluble vitamins $A$ and D and have now available for general clinical use standardised preparations of these highly important substances. The isolation of calciferol (vitamin D) by Dr. Bourdillon and his collaborators has been followed in a remarkably short space of time by its preparation on a commercial basis by British Drug Houses, Ltd., who are to be congratulated on the rapidity with which they have translated a delicate laboratory process to a works' scale. This firm now supplies, under the name of Radiostol Solution and Radiostol Pellets, pure crystalline vitamin D. The solution, the activity of which is such that one fluid ounce is equivalent to fifty fluid ounces of cod-liver oil, is a tasteless preparation of the pure vitamin in oil, while the pellets contain it incorporated in cocoa butter, one pellet being equivalent to a full adult dose of cod-liver oil.

Another physiologically standardised vitamin D product, sold under the brand name of Ostelin, emanates from the Glaxo Laboratories (Joseph Nathan and Co., Ltd.). This preparation, which was originally manufactured in 1924 from cod-liver oil but is now prepared by the carefully controlled irradiation of ergosterol, is also supplied in both liquid and tablet forms. Ostelin liquid, which is standardised to contain 5000 international units of vitamin D per c.c., is tasteless and miscible with water, and can therefore be dispensed in pharmaceutical mixtures. The tablets contain, in addition to 500 units of vitamin $\mathrm{D}$ each, neutral calcium glycerophosphate.

More recently the Glaxo Laboratories have also put on the market, under the brand name of Adexolin, a mixed preparation of both vitamins $A$ and $D$ in proportions normal to cod-liver oil. Adexolin is available both as liquid and capsules. The special feature of the liquid, a fluid oz. of which is equivalent in both vitamins to 20 fluid oz. of good cod-liver oil, is that as a result of a special process it is largely free from the objectionable taste of ordinary fish-liver oil concentrates. The capsules have been designed to allow the administration of larger quantities of the two vitamins than is necessary for infants. The prophylactic dose for adults is usually $1-3$ capsules per day, but in cases of acute septicæmia complicated by high febrile conditions, so many as 24 capsules per day can, we are informed, be administered with highly favourable results.

\section{University and Educational Intelligence}

BIrmingham.-The degree of D.Sc. has been awarded to T. L. Ibbs for various papers on thermal diffusion and the form and field of force of the carbon dioxide molecule and allied subjects.

London.-Mr. J. L. S. Hatton, principal of East London College, has been elected vice-chancellor for 1932-33 in succession to Dr. J. Scott Lidgett, whose term of office expires on Aug. 31. Dr. W. R. Halliday, principal of King's College, has been appointed deputy vice-chancellor for the same period in succession to Canon Douglas.

Prof. D. T. Harris, since 1921 assistant professor in the Institute of Physiology at University College, has been appointed professor of physiology (London Hospital Medical College) as from Oct. I.

The title of University reader has been conferred on Dr. Evelyn E. Hewer, lecturer in histology at the London (R.F.H.) School of Medicine for Women.

OXFORD,-Among the honorary degrees conferred on Jume 22 were the following: D.Se. on Sir John Russell, director of the Rothamsted Experimental Station, and Prof. Willem de Sitter, professor of astronomy in the University of Leyden; D.C.L. on Sir Arthur Salter, recently director of the Economic and Finance Section of the League of Nations.

Sir James Frazer is to deliver the Sir Basil Zaharoff lecture for this year.

THe National University of Ireland is about to enter upon its twenty-fifth year and has signalised the approach of this anniversary and "the special signific- 